ISSN 0103-8478

\title{
Formas de fósforo no solo após o cultivo de braquiária e tremoço branco
}

\author{
Soil phosphorus pools as affected by brachiaria and white lupin
}

Moniki Campos Janegitz ${ }^{I^{*}}$ Beatriz Shizue Inoue ${ }^{\mathrm{I}}$ Ciro Antonio Rosolem ${ }^{\mathrm{I}}$

RESUMO

A deficiência de fósforo $(P)$ é um dos principais fatores limitantes da produtividade em solos tropicais, mas há indicações de que algumas plantas podem melhorar a disponibilidade do $P$ no solo. $O$ trabalho teve por objetivo avaliar as transformações do $P$ durante o cultivo da braquiária e do tremoço-branco, além de um possível aumento de formas orgânicas de P no solo. $O$ experimento foi instalado em casa de vegetação, onde foram cultivados braquiária (Urochloa ruziziensis) e tremoço branco (Lupinus albus L.), fertilizados com 0; 20; 40; 60 e 80mg dm $\mathrm{dm}^{-3}$ de P. As plantas foram cultivadas por 60 dias. A adubação com $P$ aumentou a produção de matéria seca da braquiária e tremoço branco. O P bioativo (extraído com EDTA) é aumentado pelas doses de $P$, mas não é afetado pelas espécies vegetais. $O$ tremoço branco é mais eficiente em absorver o $P$, enquanto a braquiária é mais eficiente em reduzir a capacidade máxima de adsorção de $P$ do solo.

Palavras-chave: fósforo bioativo, adsorção de fósforo, fósforo orgânico, plantas de cobertura.

\section{ABSTRACT}

Phosphorus is one of the major factor that limits agricultural productivity in most tropical soils. The objective of this study was to assess $P$ transformations and availability in a soil cropped to brachiaria (Urochloa ruziziensis) and white lupin (Lupinus albus L.). The study was carried out in a greenhouse at Botucatu, State of São Paulo, Brazil. Brachiaria and white lupin were grown in pots with soil fertilized with $0,20,40,60$ and $80 \mathrm{mg} \mathrm{dm}^{-3} \mathrm{P}$. The plants were grown for 60 days, when they were harvested and the soil was sampled. Dry matter yields of both species were increased with $P$ rates. Soil bioactive $P$ is increased with $P$ fertilization, but is not affected by the plant species. White lupin is more effective in taking up the organic soil $P$, but Brachiaria was more effective in reducing the soil maximum $P$ adsorption capacity.
Key words: bioactive phosphorus, phosphorus adsorption, organic phosphorus, cover crops.

\section{INTRODUÇÃO}

A deficiência de fósforo é um dos principais fatores da baixa produtividade das culturas em solos tropicais e subtropicais. Nessas condições, o P orgânico pode ser importante na nutrição das plantas. A porção biológica do ciclo do P é controlada pela decomposição de restos culturais por bactérias e fungos, imobilização e mineralização, além de absorção pelas plantas. O P da biomassa microbiana é considerado biologicamente disponível na rizosfera, pois, pela morte dos microrganismos, ocorre a liberação do P orgânico da sua biomassa, aumentando sua disponibilidade (SOUZA et al., 2007).

As plantas diferem em sua eficiência na extração e utilização do $\mathrm{P}$ que, além de estar ligada à atividade das fosfatases (DUFF et al., 1994), depende de mecanismos como a alteração do sistema radicular (VANCE et al., 2003), liberação de exsudatos orgânicos nas raízes, tais como citrato e malato (WATTS \& EVANS, 1999) e associações simbióticas e assimbióticas com microorganimos na rizosfera (COSTA \& LOVATO, 2004), sendo capazes de reduzirem o número de sítios de sorção de P pela complexação de Fe e Al.

A exsudação de ácidos orgânicos e a mobilização do $\mathrm{P}$ através da enzima fosfatase que ocorre em plantas de tremoço branco, compensando a

'Departamento de Produção Vegetal, Faculdade de Ciências Agronômicas, Universidade Estadual Paulista “Júlio de Mesquita Filho" (UNESP), R. José Barbosa de Barros, 1780, 18610-307 Botucatu, SP, Brasil. E-mail: monikijanegitz@yahoo.com. *Autor para correspondência. 
não associação com micorriza da espécie e a ausência dos benefícios da nutrição de $\mathrm{P}$ pela associação (KLOSE \& TABATABAI, 2002). Já o número de bactérias com atividade da fosfatase ácida em solo cultivado com braquiária e guandu (Cajanus cajan) corresponde a $58,2 \%$ do total de bactérias, sendo que o maior número é encontrado em solo cultivado com a gramínea (NAHAS, 2002). Por outro lado, foi encontrada evidência de que a braquiária pode solubilizar formas não lábeis de P (MERLIN et al., 2009), o que poderá ser uma ferramenta importante no manejo do fertilizante em sistemas com rotação de culturas.

Uma vez que o uso de plantas de cobertura como braquiária e tremoço pode favorecer a solubilização ou a diminuição da adsorção do $\mathrm{P}$ no solo, resultando em maior utilização do $\mathrm{P}$ orgânico (GEORGE et al., 2006) e, consequentemente, aumentar a eficiência de uso de fertilizantes fosfatados, o objetivo do trabalho foi avaliar as transformações do $\mathrm{P}$ do solo durante o cultivo da braquiária e tremoço branco.

\section{MATERIAL E MÉTODOS}

O experimento foi realizado na Faculdade de Ciências Agronômicas, no ano de 2011, em Botucatu (SP), em casa de vegetação localizada a $22^{\circ} 51^{\prime} \mathrm{S}, 48^{\circ} 26^{\prime}$ 'W Grw e altitude de $740 \mathrm{~m}$. Foi utilizado um Latossolo Vermelho Distroférrico, de textura média, com $\mathrm{pH}\left(\mathrm{CaCl}_{2}\right) 4,5 ; 4,2 \mathrm{mg} \mathrm{dm}^{-3} \mathrm{de}$ $\mathrm{P}_{\text {resina }}, 18 \mathrm{~g} \mathrm{~kg}^{-1}$ de matéria orgânica, $9,9 \mathrm{mmol}_{\mathrm{c}} \mathrm{dm}^{-3}$ de $\mathrm{Ca}, 3,8 \mathrm{mmol}_{\mathrm{c}} \mathrm{dm}^{-3}$ de $\mathrm{Mg}, 0,7 \mathrm{mmol}_{\mathrm{c}} \mathrm{dm}^{-3}$ de $\mathrm{K}$, $33 \mathrm{mmol}_{\mathrm{c}} \mathrm{dm}^{-3}$ de $\mathrm{Al}+\mathrm{H}$, e $30 \%$ de saturação por bases. Antes da instalação do experimento, o solo ficou incubado por 60 dias com calcário dolomítico (CaO: 39\%, MgO: 13\% e PRNT: 91\%) para elevar a saturação por bases a $60 \%$. O solo recebeu adubação com $100 \mathrm{mg} \mathrm{dm}^{-3}$ de $\mathrm{Ne} 100 \mathrm{mg} \mathrm{dm}^{-3}$ de $\mathrm{K}$, como ureia e cloreto de potássio, respectivamente.

Os tratamentos constaram de cinco doses de P e cultivo de duas espécies, a braquiária (Urochloa ruzizienses) e o tremoço branco (Lupinus albus L.) $\mathrm{O} \mathrm{P}$ foi aplicado como o super fosfato triplo, nas doses 0; 20; 40; 60 e $80 \mathrm{mg} \mathrm{dm}^{-3} \mathrm{de}$ P. As sementes de braquiária e tremoço foram submetidas à quebra de dormência. A quebra de dormência das sementes de braquiária foi realizada por imersão em ácido sulfúrico concentrado por 10 minutos, com posterior lavagem em água destilada. As sementes de tremoço branco foram armazenadas em geladeira $\left(4^{\circ} \mathrm{C}\right)$ por 15 dias. Em seguida, as sementes foram pré-germinadas por 48 horas a $25^{\circ} \mathrm{C}$ e a semeadura foi realizada manualmente, com 10 sementes prégerminadas por vaso. Após oito dias da semeadura, foram selecionadas quatro plântulas por parcela que foram cultivadas até 60 dias após o transplante (DAT). A umidade do solo foi monitorada e mantida entre 70 e $100 \%$ da capacidade de retenção dos solos, por meio de pesagens e regas diárias.

A determinação do $\mathrm{P}$ orgânico seguiu a metodologia de OLSEN \& sommers (1982), sendo a extração realizada com $\mathrm{H}_{2} \mathrm{SO}_{4} 0,5 \mathrm{~mol} \mathrm{~L}^{-1}$. Para análise do P bioativo, como definido por DAO (2004), as amostras de solo foram secas em estufa a $65^{\circ} \mathrm{C}$ por 48 horas, moídas e peneiradas em malha de $2 \mathrm{~mm}$. Nessas amostras, foi determinado o P extraível em EDTA $0,005 \mathrm{~mol} \mathrm{~L}^{-1}$, através de agitação por uma hora na relação 1:100 (massa:volume). Após a agitação, estas foram centrifugadas a 10.000 rpm por $10 \mathrm{~min}$ e foi tomado o sobrenadante para análise. Na fração EDTA, foram adicionadas posteriormente a enzima fitase (EC 3.1.3.8 Sigma-Aldrich), com agitação por $18 \mathrm{~h}$ em agitador horizontal, com posterior centrifugação e coleta do sobrenadante (DAO, 2004). A fitase é usada para degradação de parte da fração orgânica do $\mathrm{P}$ do solo, e então é determinado o P orgânico. A fração determinada após a adição da fitase é o chamado $\mathrm{P}$ bioativo do solo e é considerado disponível para as plantas (DAO, 2004).

A capacidade máxima de adsorção de $\mathrm{P}$ do solo (CMAP) foi determinada através da agitação de solução contendo $10,20,40$ e $80 \mathrm{mg} \mathrm{L}^{-1}$ de $\mathrm{P}$, juntamente com amostras de solo, na proporção de 1:10 (solo:solução) durante 48 horas, sob rotação de 150rpm em agitador horizontal. Depois disso, as amostras foram centrifugadas a $3.000 \mathrm{~g}$ por $10 \mathrm{~min}$ e quantificado o $\mathrm{P}$ remanescente. Todas as frações de $\mathrm{P}$ foram determinadas por colorimetria, pelo método do Molibdato-ácido ascórbico (MURPHY \& RILEY, 1962). Aos 60DAT, as plantas foram cortadas no nível do colo e a parte aérea foi seca em estufa com circulação forçada de ar a $65^{\circ} \mathrm{C}$ por 72 horas. A seguir, foram pesadas, digeridas em mistura nitro/perclórica e foi analisado o teor de $\mathrm{P}$ total no tecido por colorimetria, (MALAVOLTA et al., 1997).

O experimento foi conduzido em blocos inteiramente casualizados, com quatro repetições. Os resultados foram submetidos à análise de variância e as médias comparadas pelo teste $\mathrm{t}$ (LSD) a $5 \%$ de probabilidade. Com aplicação de análise de regressão para as doses de $\mathrm{P}$.

\section{RESULTADOS E DISCUSSÃO}

Ambas as plantas de cobertura responderam à adubação fosfatada de forma quadrática. A máxima produção de matéria seca foi observada com doses de 
60 a $80 \mathrm{mg} \mathrm{dm}^{-3} \mathrm{de} \mathrm{P}$ (Figura 1a). Os teores de P na parte aérea das plantas foram aumentados linearmente com a aplicação de $\mathrm{P}$, mas não foi observada diferença significativa entre as espécies (Figura 1b). Nas doses mais baixas de $\mathrm{P}\left(0\right.$ e $\left.20 \mathrm{mg} \mathrm{dm}^{-3}\right)$, a braquiária produziu maior matéria seca, quando comparada ao tremoço branco, ainda que os teores do nutriente na parte aérea tenham sido semelhantes. Resultados condizentes foram observados por ROSSI et al. (1999) e BOLLAND (1997), que, estudando doses de $\mathrm{P}$, observaram incrementos quadráticos na produção de matéria seca e aumento linear na concentração de $\mathrm{P}$ nas folhas de algumas espécies de forrageiras e tremoço branco, respectivamente.

Embora tenha ocorrido aumento na produção de matéria seca com maiores teores de $\mathrm{P}$, os teores observados na braquiária estiveram acima da faixa de suficiência indicada para as gramíneas, que varia de 0,6-1,1. $\mathrm{g} \mathrm{k}^{-1}$ (MALAVOLTA et al., 1997), enquanto que, para o tremoço, teores de $\mathrm{P}$ acima de $2,0 \mathrm{~g} \mathrm{~kg}^{-1}$ seriam adequados (KEERTHISINGHE et al., 1998).

As braquiárias são bem adaptadas a condições de baixa fertilidade do solo e, portanto, eficientes na aquisição do $\mathrm{P}$ do solo. Quando cultivada em ambiente com baixa disponibilidade de $\mathrm{P}$, foi observada maior quantidade de $\mathrm{P}$ microbiano no solo, além de maior atividade de fosfatase ácida na rizosfera de B.ruziziensis e maior quantidade de P orgânico, o que certamente explica sua maior eficiência em absorver o nutriente quando em baixa disponibilidade (MERLIN et al., 2009). Nem sempre tem sido observada resposta do tremoço branco ao P (WATT \& EVANS, 2003), o que se atribui à sua arquitetura radicular, uma vez que se encontram nessa espécie raízes específicas denominadas de cluster roots, que são capazes de exsudar ânions orgânicos que ocupam os sítios de adsorção de $\mathrm{P}$ do solo, disponibilizando-o para as plantas em condições de deficiência (SHANE \& LAMBERS, 2005). Por outro lado, em condições de alta disponibilidade de $\mathrm{P}$, ocorre redução no número dessas raízes específicas e, consequentemente, menor produção de ácidos orgânicos e maior adsorção de P (NEUMANN et al., 1999).

A menor produção de matéria seca do tremoço nas menores doses de $\mathrm{P}$ pode ser explicada em função da baixa disponibilidade do nutriente, pois ocorreu diminuição ou mesmo a isenção de fixação, não havendo $\mathrm{P}$ a ser adsorvido (Figura 1a). Com a aplicação de $\mathrm{P}$ e, portanto, maior disponibilidade do nutriente, pode ter ocorrido menor adsorção na presença do tremoço branco, de modo que a produção de matéria seca dessa planta se igualou à da braquiária entre as doses de 40-60 $\mathrm{mg} \mathrm{dm}^{-3}$.

Existem plantas de cobertura capazes de alterar o pH do solo, que geralmente é menor na rizosfera (SOUZA \& ALVES, 2003), o que pode afetar a disponibilidade do P. Como no presente experimento o sistema radicular estava confinado no vaso, seria possível que esse efeito fosse notado no solo, o que, contudo, não foi observado (Tabela 1). Portanto os efeitos sobre as formas de $\mathrm{P}$ não devem ter sido alterados pelo $\mathrm{pH}$ do solo.

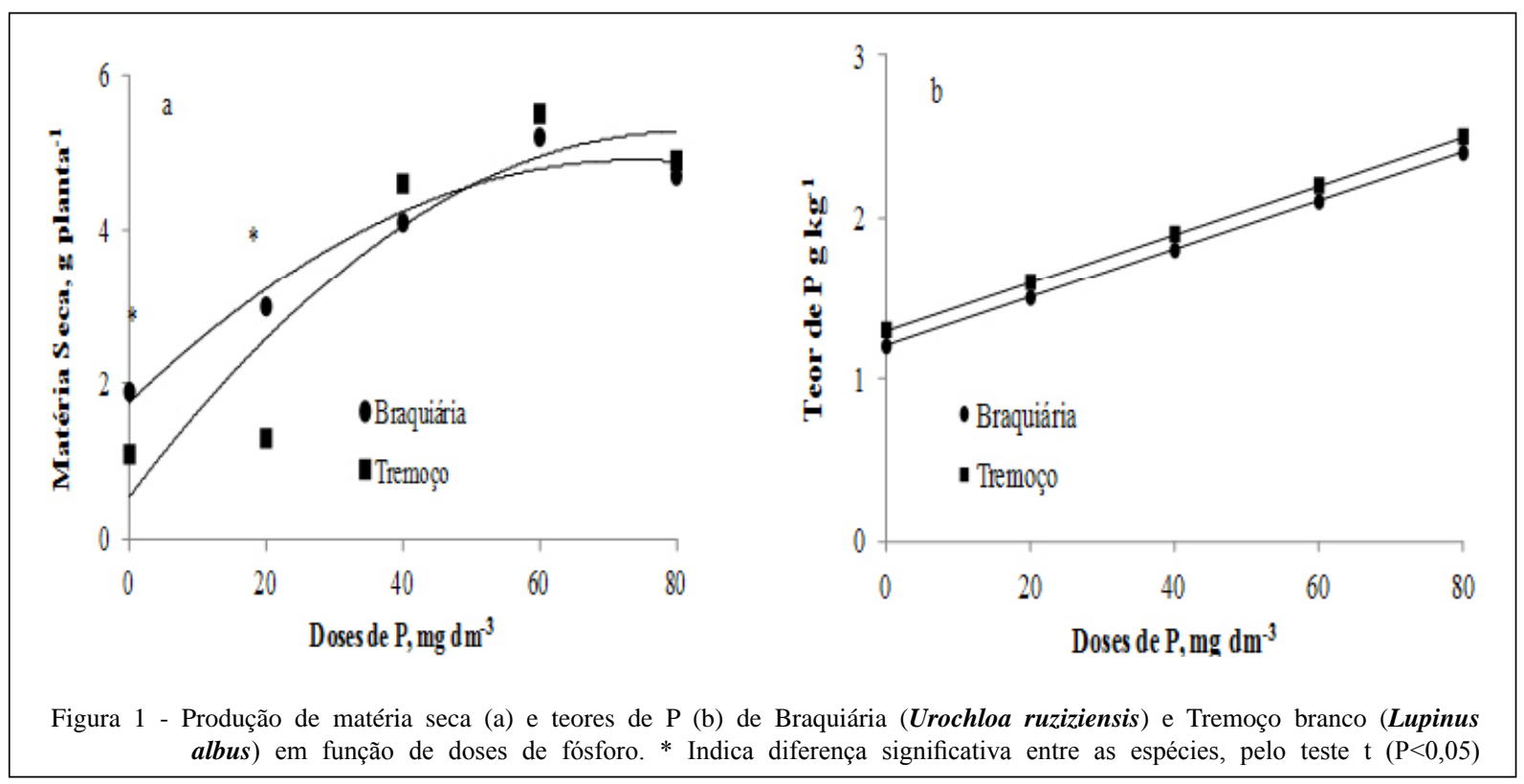

Ciência Rural, v.43, n.8, ago, 2013. 
Tabela 1 - Valores médios de $\mathrm{pH}\left(\mathrm{CaCl}_{2}\right)$, $\mathrm{P}$ bioativo (PHP) e $\mathrm{P}$ orgânico do solo em função de dose de $\mathrm{P}$ e o cultivo de braquiária (BR) (Urochloa ruziziensis) e Tremoço branco (TB) (Lupinus albus).

\begin{tabular}{|c|c|c|c|c|c|c|}
\hline \multirow{2}{*}{$\frac{\text { Doses de P }}{\left(\mathrm{mg} \mathrm{dm}^{-3}\right)}$} & \multicolumn{2}{|c|}{ 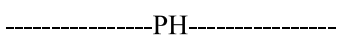 } & \multicolumn{2}{|c|}{-----P bioativo (ppm) ------ } & \multicolumn{2}{|c|}{--------P orgânico (ppm)-------- } \\
\hline & $\mathrm{BR}$ & $\mathrm{TB}$ & BR & $\mathrm{TB}$ & BR & $\mathrm{TB}$ \\
\hline 0 & 5,2 & 5,4 & 1,4 & 1,5 & 95,4 & $89,1^{*}$ \\
\hline 20 & 5,3 & 5,3 & 3,4 & 3,5 & 94,6 & $91,7^{*}$ \\
\hline 40 & 5,2 & 5,3 & 5,5 & 5,8 & 95,5 & 92,6 \\
\hline 60 & 5,2 & 5,3 & 7,2 & 7,9 & 95,6 & 93,4 \\
\hline 80 & 5,2 & 5,2 & 12,7 & 11,1 & 96,9 & 95,2 \\
\hline Médias & 5,2 & 5,3 & 6,0 & 5,9 & 95,2 & 92,4 \\
\hline $\mathrm{DMS}^{(1)}$ & ns & ns & 1,2 & 1,5 & $\mathrm{~ns}$ & 2,4 \\
\hline
\end{tabular}

(1) $\mathrm{e}$ * Diferença mínima significativa a 5\% de probabilidade de erro, pelo teste $\mathrm{t}$; ns não significativo, respectivamente nas colunas e entre espécies.

A adubação fosfatada resultou em maiores valores de P bioativo (Tabela 1). Os valores de PHP indicam que o solo apresenta quantidade considerável de P orgânico, que está ativo e poderia estar disponível para as plantas, como proposto por DAO (2004). Como não houve diferença entre as espécies, pode-se inferir que essas plantas foram equivalentes quanto ao uso eficiente do P dessa fração. A utilização de extrator EDTA junto à enzima fitase resultou em melhoria na determinação do P realmente disponível às plantas em solos americanos, já em solos brasileiros os resultados não foram satisfatórios (DAO, 2004; PAVINATO et al., 2010). As dificuldades de se observar esta fração nos solos brasileiros estão relacionadas aos teores de argila e às quantidades consideráveis de $\mathrm{Fe}$ e $\mathrm{Al}$, que consequentemente diminuem a fração de $\mathrm{P}$ disponível, devido à maior capacidade de adsorção nos coloides.

O solo cultivado com tremoço branco apresentou menores valores de $\mathrm{P}$ orgânico, principalmente com as menores doses de fertilizante fosfatado (Tabela 1). A exsudação de ácidos orgânicos, tais como citrato e malato (WATTS \& EVANS, 1999), além da mobilização do P através da enzima fosfatase são bem conhecidas em plantas de tremoço branco. Assim, haveria solubilização do $\mathrm{P}$ do solo e redução dos sítios de sorção de $\mathrm{P}$ pela complexação com $\mathrm{Fe}$ e $\mathrm{Al}$, efeito possivelmente observado, uma vez que o solo cultivado com tremoço apresentou $89,1 \mathrm{mg} \mathrm{dm}^{-3}$ e com a braquiária $95,4 \mathrm{mg} \mathrm{dm}^{-3}$ de $\mathrm{P}$ orgânico, na ausência de aplicação de P. Entretanto, a atividade das fosfatases, ou mesmo a exsudação de ácidos orgânicos, mobilizou o P do solo cultivado com tremoço, favorecendo a transformação da fração não lábil para a fração lábil desse nutriente. $\mathrm{O}$ efeito de plantas de cobertura e o acúmulo de nutrientes, se em torno de $1000 \mathrm{mg} \mathrm{kg}^{-1}$, também com resposta quadrática . Já foi observado por SILVA et al. (1997) que o cultivo de gramíneas (B. ruziziensis) resulta geralmente em menor CMAP do solo em relação às leguminosas (Figura 2). Comparativamente às leguminosas, as gramíneas produzem mais raízes, as quais, decompostas no solo, contribuem com o carbono, que poderia ocupar sítios de adsorção. Além disso, as raízes de gramíneas contribuem com

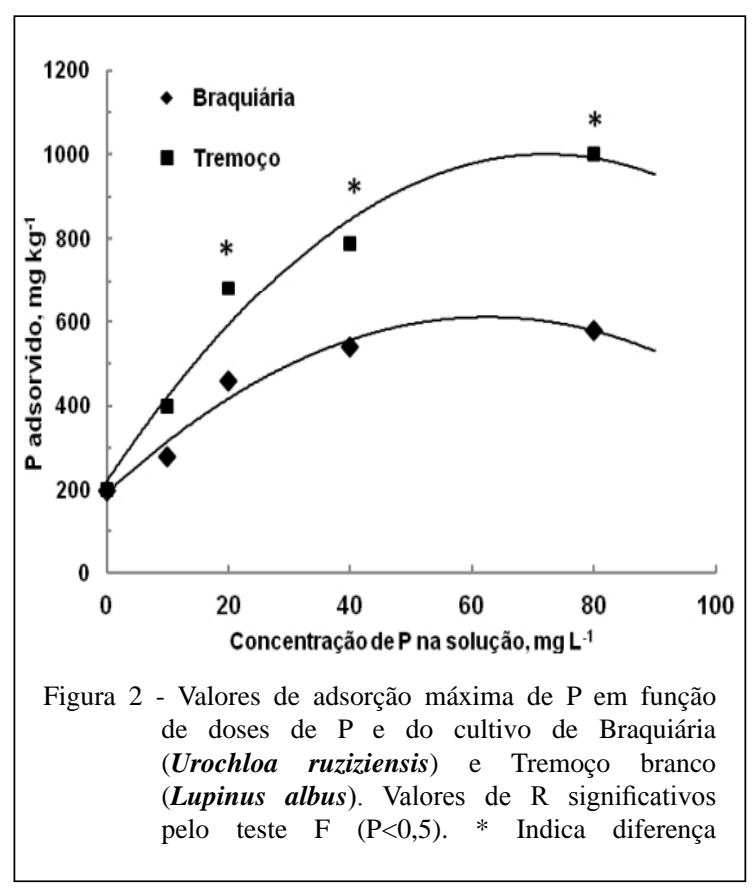

Ciência Rural, v.43, n.8, ago, 2013. 
maior quantidade de ácidos fenólicos para a matéria orgânica do solo (DALTON et al., 1989), bloqueando parte dos sítios de sorção de P. Por outro lado, foi encontrado maior número de bactérias com atividade da fosfatase ácida em solo cultivado com a gramínea (NAHAS, 2002).

\section{CONCLUSÃO}

O fósforo bioativo do solo é aumentado com a aplicação de fertilizante fosfatado, mas não é modificado com o cultivo da braquiária ou do tremoço branco. O cultivo de tremoço branco resulta em menor teor de fósforo orgânico do solo quando há pouco fósforo disponível, mas o cultivo de braquiária reduz a capacidade máxima de adsorção de fósforo do solo.

\section{REFERÊNCIAS}

BOLLAND, M.D.A. Comparative phosphorus requirements of five annual medics. Journal of Plant Nutrition, v.20, n.09, p.1029-1043, 1997. Disponível em: <http: //dx.doi.org /10.1080/01904169709365316>. Acesso em: 20 mar. 2012. doi:10.1080/01904169709365316.

COSTA, D.M.; LOVATO, P.E. Fosfatases na dinâmica do fósforo no solo sobre culturas de cobertura com espécies micorrizicas e não micorrízicas. Pesquisa Agropecuária Brasileira, v.39, n.6, p.603-605, 2004. Disponível em: <http:// dx.doi.org/10.1590/S0100-204X2004000600013>. Acesso em: 25 mar. 2012. doi: 10.1590/S0100-204X2004000600013.

DALTON, B.R. et al. Differential sorption of exogenously applied ferulic, p-coumaric, p-hydroxybenzoic andvanillic acids in soil. Soil Science Society of America Journal, v.53, p.757-762, 1989. Disponivel em: <http://dx.doi.org/ 10.1007/BF02220689>. Acesso em: 1 abr. 2012. doi: 10.1007/ BF02220689.

DAO, T.H. Ligands and phytase hydrolysis of organic phosphorus in soils amended with dairy manure. Agronomy Journal, v.96, p.1188-1195, 2004. Disponível em: <https: // www.agronomy.org/publications/aj/abstracts/96/4/1188>. Acesso em: 04 abr. 2012. doi: 10.2134/agronj2004.1188.

DUFF, S.M.G. et al. The role of acid phosphatases in plant phosphorus metabolism. Physiologia Plantarum, v.90, p.791-800, 1994. Disponível em: <http://dx.doi. org/10.1111/j.1399-3054.1994.tb02539.x>. Acesso em: 23 jul. 2012. doi: 10.1111/j.1399-3054.1994.tb02539.x.

GEORGE, T.S. et al. Depletion of organic phosphorus from Oxisols in relation to phosphatase activities in therhizosphere. European Journal of Soil Science, v. 57, p.47-57, 2006. Disponivel em: <http://onlinelibrary.wiley.com/doi/10.1111/ j.1365-2389.2006.00767PubMed.x/pdf $>$. Acesso em: 14 maio 2012. doi: 10.1111/j.1365-2389.2005.00767.x.

KEERTHISINGHE, G. et al. Effect of phosphorus supply on the formation and function of proteoid roots of white lupin (Lupinus albus L.). Plant, Cell and Environment, v.21, p.467-478, 1998. Disponível em: <http://onlinelibrary.wiley. com/ doi/10.1046/j.1365-040.1998.00300.x/pdf >. Acesso em: 13 jun. 2012. doi:10.1046/ j.1365-3040.1998.00300.x.

KLOSE, S.; TABATABAI, M.A. Response of phosphomono esterases in soils to chloroform fumigation. Journal Plant Nutrition and Soil Science, v.165. p.429-434, 2002. Disponível em: <http://dx.doi.org/10.1002/15222624(200208)165:4429::AID-JPLN4293.0.CO;2-S>. Acesso em: 21 jul. 2012. doi: 10.1002/1522-2624(200208)165:4<429::AIDJPLN429>3.0.CO;2-S.

MALAVOLTA, E. et al. Avaliação do estado nutricional das plantas: princípios e aplicações. 2.ed. Piracicaba: POTAFOS, 1997. 317p.

MERLIN, A. et al. Soil phosphorus forms after brachiaria. In: INTERNATIONAL PLANT NUTRITION COLLOQUIUM, 16. 2009, Davis. Proceedings... Davis: Department of Plant Sciences, 2009. Disponivel em: 〈http://escholarship.org/uc/item/6rf8j1tz>. Acesso em: 30 mar 2012

MURPHY, J.; RILEY, J.P. A modified single solution method for the determination of phosphate in natural waters. Analytica Chimica Acta, v.27, p.31-36, 1962. Disponível em: <http://dx.doi. org/10.1016/j.bbr.2011.03.031>. Acesso em: 20 nov. 2010. doi: 10.1016/j.bbr.2011.03.031.

NAHAS, E. Microorganismos do solo produtores de fosfatases em diferentes sistemas agrícolas. Bragantia, v.61, n.3, p.267275, 2002. Disponivel em: <http://dx.doi.org/10.1590/S000687052002000300008>. Acesso em: 12 dez. 2011. doi: 10.1590/ S0006-87052002000300008.

NEUMANN G.et al. Physiological adaptations to phosphorus deficiency during proteoid root development in white lupin. Planta, v.208, p.373-382, 1999. Disponível em: <http://dx.doi. org/doi:10.1007/s004250050572>. Acesso em: 20 jan. 2012. doi: $10.1007 / \mathrm{s} 004250050572$.

NURUZZAMAN, M. et al. Phosphorus uptake by grain legumes and subsequently grown wheat at different levels of residual phosphorus fertiliser. Australian Journal of Agricultural Research, v.56. p.1041-1047, 2005. Disponível em: <http:// dx.doi.org/10.1071/AR05060>. Acesso em: 28 jun. 2011. doi: 10.1071/AR05060.

OLSEN, S.R.; SOMMERS, L.E. Phosphorus. In: PAGE, A.L. et al. (Ed.). Methods of soil chemical analysis. Part 2: Microbial and Microbiological Properties (Agronomy). Madison: Am Soc Agron, 1982. V.9, p.403-430.

PAVINATO, P.S.; ROSOLEM, C.A. Disponibilidade de nutrientes no solo - decomposição e liberação de compostos orgânicos de resíduos vegetais. Revista Brasileira de Ciência do Solo, v.32, n.3, p.911-920, 2008. Disponível em: <http://dx.doi.org/10.1590/ S0100-06832008000300001>. Acesso em: 19 jan. 2012. doi: 10.1590/S0100-06832008000300001.

PAVINATO, P.S. et al. Tillage and phosphorus management effects on enzyme-labile bioactive phosphorus availability in Cerrado Oxisols. Geoderma, v.156, p.207-215, 2010. Disponível em: <http://dx.doi.org/10.1016/j.bbr.2011.03.031. Acesso em: ago. 2011. doi: 10.1016/j.bbr.2011.03.031.

ROSSI, C. et al. Efeito residual de fertilizantes fosfatados para o arroz: avaliação do fósforo na planta e no solo por diferentes 
extratores. Scientia Agricola, v.56, p.39-46, 1999. Disponível em: <http://dx.doi.org/10.1590/S0103-90161999000100007>. Acesso em: 23 jul. 2012. doi: 10.1590/S0103-90161999000100007.

SHANE, M.W.; LAMBERS, H. Cluster roots: a curiosity in context. Plant and Soil, v.274, p.101-125, 2005.

SILVA, M.L.N. et al. Rotação adubo verde-milho e adsorção de fósforo em latossolo vermelho-escuro. Pesquisa Agropecuária Brasileira, v.32, n.6, p.7, 1997.

SOUZA, Z.M.; ALVES, M.C. Propriedades químicas de um Latossolo Vermelho distroférrico de cerrado sob diferentes usos e manejos. Revista Brasileira de Ciência do Solo, v.27, p.133139, 2003. Disponivel em: <http://redalyc.uaemex.mx/src/inicio/ ArtPdfRed.jsp?iCve=180217698014>. Acesso em: 25 jun. 2011.

SOUZA, R.F. et al. Formas de fósforo em solos sob a influência da calagem e adubação orgânica. Revista Brasileira de Ciência do Solo, v.31, n.6, p.1535-1544, 2007.
Disponível em: <http://redalyc.uaemex.mx/src/inicio/ArtPdfRed. jsp?iCve=180217698014>. Acesso em: 23 jun. 2011.

VANCE C.P. et al. Phosphorus acquisition and use: critical adaptations by plants for securing a nonrenewable resource. New Phytologist, v.157, p.423-447, 2003. Disponível em: <http://dx.doi. org/10.1046/j.1469-8137.2003.00695.x>. Acesso em; 25 Jul. 2011. doi: 10.1046/j.1469-8137.2003.00695.x.

WATT, M.; EVANS, J.R. Proteoid roots physiology and development. Plant Physiology, v.121, p.317-323, 1999. Disponível em: <http: http://dx.doi.org/10.1104/pp.121.2.317>. Acesso em: 15 out. 2010. doi: $10.1104 / p p .121 .2 .317$.

WATT, M.; EVANS, J.R. Phosphorus acquisition from soil by white lupin (Lupinus albus L.) and soybean (Glycine max L.), species with contrasting root development. Plant and Soil, v.248: p.271-283, 2003. Disponível em: <http://dx.doi.org/10.1023/A:1022332700686>. Acesso em: 10 abr 2011. doi: 10.1023/A:1022332700686. 